\title{
Study of dispensary patients of working age with circulatory system diseases through the automated control systems
}

\author{
I. Abdikadirova ${ }^{1}$, A.S. Chukmaitov ${ }^{2}$, L. Yermukhanova ${ }^{1}$, and A. Bekbauova ${ }^{1}$ \\ ${ }^{1}$ West Kazakhstan Marat Ospanov State Medical University, The Republic of Kazakhstan \\ ${ }^{2}$ Virginia Commonwealth University School of Medicine, USA
}

\begin{abstract}
Diseases of the circulatory system occupy a leading position among the diseases prevalence of which is increasing with each passing year and is sustainable. The leading reasons for the circulatory diseases as revealed by prophylactic medical examination are arterial hypertension, chronic heart failure, arrhythmia and coronary heart disease. The growth in the number of circulatory system diseases causes medical and social problem - disability of the working-age population. In order to determine the role of Automated Control System the study of morbidity, disability and mortality due to circulatory system diseases was conducted in the municipal polyclinic No. 4 of Aktobe city (West Kazakhstan). The method of retrospective data analysis of annual statistical reports and data from the portal "Electronic Register of dispensary patients", "Automated Information System", "Drug Supply Information System" was used. The incidence of circulatory system diseases in dispensary patients of working age had risen from $1.94 \%$ o (2011) to $2.8 \%$ (2015). In the main classes of primary disability the circulatory system diseases in terms of growth steadily occupy the first place ranking.
\end{abstract}

Key words: automated control system, circulatory system diseases, morbidity, disability.

\section{Introduction}

In modern conditions the most urgent problem of public health and health care is the health of the working age population.

The second half of the $20^{\text {th }}$ century and the beginning of the $21^{\text {st }}$ century in many countries around the world along with real positive achievements in the prevention and treatment of many diseases are marked with increase in morbidity and disability in the population (including that caused by the circulatory system diseases).

Cardio-vascular diseases are a major problem of public health worldwide [1], as the number of patients with cardio-vascular diseases is constantly increasing and increases with age [2].

The territorial computerized register of all contingents of dispensary for diseases was established in the Republic of Kazakhstan [3]. In all medical institutions, patients with circulatory system diseases are a subject to dispensary observation. Prophylactic medical examination is the method of active dynamic hospital observation of the health of 
population groups with chronic illnesses [4]. The study of morbidity of patients under the dispensary observation will improve health outcomes and make it possible to evaluate the effectiveness of prophylactic medical examination. Improving the efficiency of dispensary observation remains one of the topical problems of modern health care of the Republic of Kazakhstan primarily in connection with prevalence of chronic non-communicable diseases among the working-age population. Organization of prophylactic clinical examination requires much time for completing the documentation, accounting and reporting. Currently information technologies are widely used in health care as it allows automation of physicians' activities and improves the quality and efficiency of their work; they help to move from paper to modern technologies of data storage and processing.

State programme of reforming and development of health care of Kazakhstan from September 13, 2004 No. 1438 covers the establishment of the Unified Health Management Information System of Kazakhstan which resulted in the introduction of information technologies in health care and the establishment of the National Information and Analytical Center with branches in all regions.

Implementation of automated control systems in the health care of Kazakhstan is a necessary process, as it provides computer support for medical decisions in diagnosis, clinical examination of the various population groups, as well as providing management decision-making in health care.

Automated control system is aimed at improving the management healthcare and improving the quality and accessibility of health aid. Automated control system will ease conducting of a complete medical electronic document management, it will help to get rid of the chore of keeping documentation and focus on the patient's problems [5].

According to the Order No. 71 from February 6, 2014 "Electronic Register of dispensary patients" was introduced.

Portal "Electronic Register of Dispensary Patients" is the system of dispensary patients' records. Daily work of medical clinics in conducting dispensary card is fully automated in the programme with the formation of statistical and operational reports.

To improve the system of drug provision for population in the framework of guaranteed free medical care, the Order No. 446 from September, 42009 "On approval of the list of drugs and medical products for free preferential provision of population within the guaranteed volume of free medical care on dispensary basis" was issued. In accordance with the above mentioned orders, dispensary patients having circulatory system diseases with only four nosologies: hypertension, coronary heart disease, arrhythmia, chronic heart failure are provided by free drugs.

Nowadays cardio-vascular diseases are one of the most common cause of mortality all over the world $[6,7]$, they are also the main reason of disability which requires socioeconomic resources [8]. One of the indicators characterizing the medical and social significance of the problem is a high rate of primary disability of patients with these diseases. Cardio-vascular diseases such as coronary heart disease and hypertension are major causes of people's disability in regions.

The purpose of this work - to study morbidity, primary disability and efficacy of rehabilitation in dispensary patients of working age with cardiovascular disease using the automated control system programmes.

\section{Materials and methods}

We conducted a retrospective analysis of morbidity and disability due to the most common diseases of the circulatory system in the structure of dispensary patients of Aktobe municipal polyclinic No. 4 in the period of 2011-2015 years. Sources of research have been the analysis of the data of annual statistical reports and data from the portal "Electronic 
Register of dispensary patients", “Automated Information System”, "Information system of drug supply". Dynamics of morbidity due to circulatory system diseases was studied over the past 5 years (2011-2015), the incidence trends are determined by least squares. In conventional methods of biomedical statistics, extensive EI and rough indicators RI of circulatory system diseases are calculated. The average age of the patients $(M)$, confidence interval $(95 \% \mathrm{CI})$ and the average annual growth rate (TPA \%) are determined.

Indicators of general and primary morbidity are calculated for 100,000 of the adult population, disability is for 100,000 of the adult population.

\section{Results and discussion}

Total number of patients 36,643 within 5 years (2011-2015) were registered in municipal policlinic No. 4 of Aktobe Republic of Kazakhstan, among them patients with the first-ever diagnosis of circulatory system diseases -4974 and dispensary patients $-20,646$ (Table 1).

Table 1. Structure of morbidity due to systemic blood circulation diseases in municipal polyclinic No. 4 Aktobe in 2011-2015.

\begin{tabular}{|c|c|c|c|c|c|c|c|c|}
\hline Years & \multicolumn{2}{|c|}{ Total (women) } & \multicolumn{2}{|c|}{$\begin{array}{c}\text { Newly diagnosed } \\
\text { (including women) }\end{array}$} & \multicolumn{2}{c|}{$\begin{array}{c}\text { Dispensary } \\
\text { registered } \\
\text { (including } \\
\text { women) }\end{array}$} & $\begin{array}{c}\text { Average } \\
\text { age } \\
(\mathbf{9 5 \%} \text { CI) }\end{array}$ & $\begin{array}{c}\text { MP- } \\
(\mathbf{9 5 \%} \text { CI) }\end{array}$ \\
\hline $\mathbf{2 0 1 1}$ & 6399 & $\begin{array}{c}3570 \\
(55.8 \%)\end{array}$ & 765 & $\begin{array}{c}408 \\
(53.3 \%)\end{array}$ & 2846 & $\begin{array}{c}1719 \\
(60.4 \%)\end{array}$ & $\begin{array}{c}55.5 \\
(55.1-55.8)\end{array}$ & $\begin{array}{c}8.72 \\
(8.52-8.93)\end{array}$ \\
\hline $\mathbf{2 0 1 2}$ & 6502 & $\begin{array}{c}3610 \\
(55.5 \%)\end{array}$ & 804 & $\begin{array}{c}457 \\
(56.8 \%)\end{array}$ & 3221 & $\begin{array}{c}1889 \\
(58.6 \%)\end{array}$ & $\begin{array}{c}52.7 \\
(52.4-53.1)\end{array}$ & $\begin{array}{c}8.49 \\
(8.30-8.7)\end{array}$ \\
\hline $\mathbf{2 0 1 3}$ & 6799 & $\begin{array}{c}3878 \\
(57 \%)\end{array}$ & 846 & $\begin{array}{c}504 \\
(59.6 \%)\end{array}$ & 3289 & $\begin{array}{c}1921 \\
(58.4 \%)\end{array}$ & $\begin{array}{c}52.5 \\
(52.2-52.8)\end{array}$ & $\begin{array}{c}8.81 \\
(8.62-9.02)\end{array}$ \\
\hline $\mathbf{2 0 1 4}$ & 7732 & $\begin{array}{c}5123 \\
(66.2 \%)\end{array}$ & 1356 & $\begin{array}{c}625 \\
(46.1 \%)\end{array}$ & 4761 & $\begin{array}{c}2682 \\
(56.3 \%)\end{array}$ & $\begin{array}{c}51.9 \\
(51.6-52.2)\end{array}$ & $\begin{array}{c}9.86 \\
(9.65-10.07)\end{array}$ \\
\hline $\mathbf{2 0 1 5}$ & 9211 & $\begin{array}{c}5932 \\
(64.4 \%)\end{array}$ & 1203 & $\begin{array}{c}725 \\
(60.3 \%)\end{array}$ & 6529 & $\begin{array}{c}3945 \\
(60.4 \%)\end{array}$ & $\begin{array}{c}52.1 \\
(51.8-52.4)\end{array}$ & $\begin{array}{c}11.95 \\
(11.72-12.18)\end{array}$ \\
\hline Total & 36643 & 22113 & 4974 & 2719 & 20646 & 12156 & $\mathrm{M}=52.7$ & $\mathrm{M}=9.56$ \\
\hline
\end{tabular}

Distribution of patients with circulatory system diseases by sex in 2011was the following: women $-55.8 \%, 2012-55.5 \%, 2013-57 \%, 2014-66.2 \%$ and in $2015-$ $64.4 \%$ with increasing prevalence of female population (Table 1). The average age of patients was $52.7 \pm 7.1$ and dynamics tended to decrease with $56.6 \pm 7.6$ in 2011 and $52.6 \pm$ 7.8 in 2015 when levelling these indicators noted above trend (Tub $=-1.4 \%)$, i.e. there is a shift in the direction of "rejuvenation". The average rough indicator (R.I.) incidence of systemic blood circulation disease was $9.56 \pm 1.43 \mathrm{o} /$ oooo. In rough indicator (R.I.) dynamics tended to grow: 8.72 in 2011 year to 11.95 in 2015 year.

In the study of the incidence of systemic blood circulation disease in dispensary patients of working age, this figure has tended to rise from $8.72 \%$ (2011) to $11.95 \%$ (2015) (Fig. 1). 


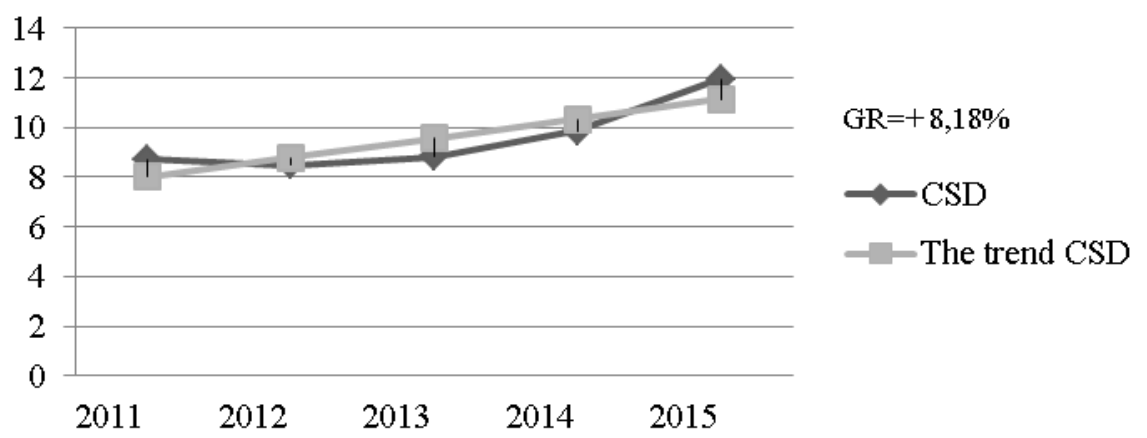

Fig. 1. The trend of overall morbidity of systemic blood circulation diseases in patients of municipal polyclinic No. 4 in Aktobe for 5 years.

When aligning number of indicators of the dynamic series, there is a tendency towards increase in the incidence of systemic blood circulation disease levels by an average of $8.18 \%$ annually. The maximum incidence is set in the age group 59-63 years (Fig. 2) with an increase in the growth rate GR $=+4.7 \%$, which resulted in a general increase in the incidence of systemic blood circulation disease in all categories of the population.

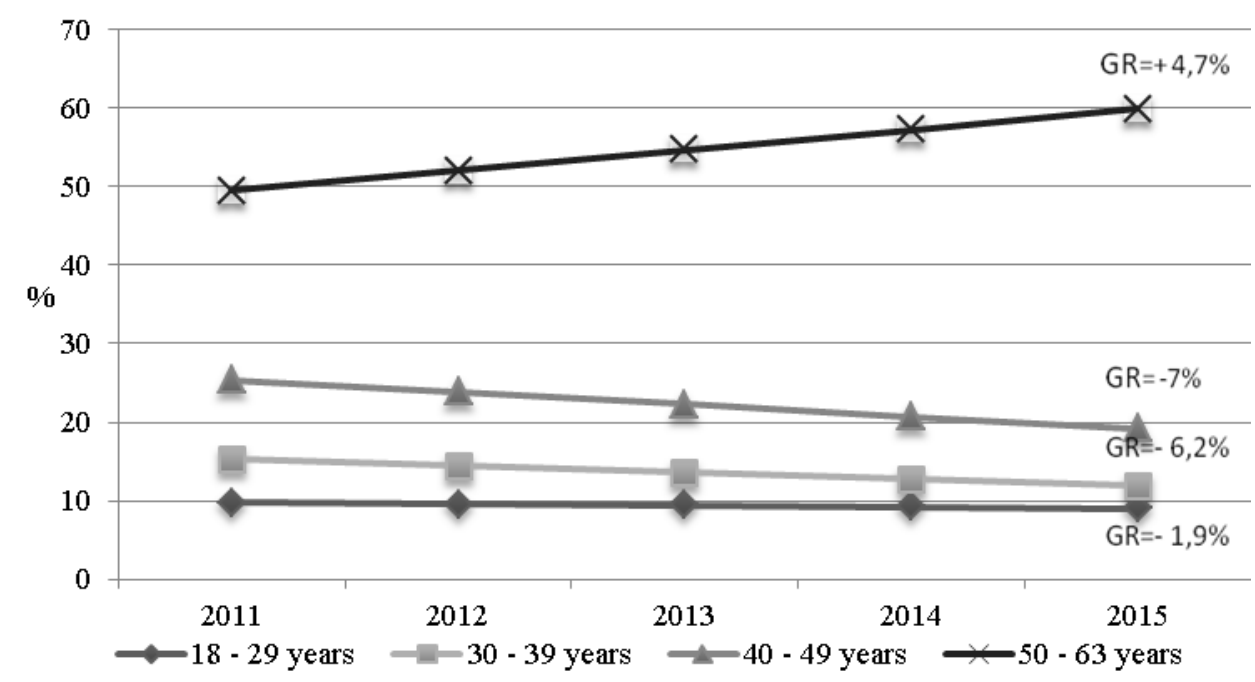

Fig. 2. The trend morbidity of systemic blood circulation disease incidence by age groups in patients of municipal polyclinic No. 4 in Aktobe for 5 years.

At the same time, trends in other age groups declined. But in general, the highest incidence rate for 5 years accounts for 2014. The average age of the patients remains almost unchanged $56.6 \pm 7.6$ in 2011 and $52.6 \pm 7.8$ in 2015.

Received results are presented in Table 2.

In the structure of patients in the dispensary of the circulatory system diseases, the largest number of patients is patients with high blood pressure and coronary heart disease. The number of patients with these nosological forms is growing, both among the indicators of general morbidity and primary morbidity. The prevalence of hypertension was 1595.3 in 2011 and 6716.2 in 2015 (100,000 people), which means increase by $32.3 \%$, in connection with which the pace of growth took first place ranking; in second place - ischemic heart 
Table 3. Dynamics in prevalence of morbidity and rate increase in the most frequent diseases among dispensary patients with circulatory system diseases for 2011-2015 years, municipal polyclinic No. 4 of Aktobe (for 100,000 people).

\begin{tabular}{|l|l|l|l|l|l|c|}
\hline Years & $\mathbf{2 0 1 1}$ & $\mathbf{2 0 1 2}$ & $\mathbf{2 0 1 3}$ & $\mathbf{2 0 1 4}$ & $\mathbf{2 0 1 5}$ & $\begin{array}{c}\text { Temp } \\
\text { growth } \\
\text { \% }\end{array}$ \\
\hline $\begin{array}{l}\text { Circulatory } \\
\text { system diseases } \\
\text { (total) }\end{array}$ & 3880.5 & 4209.8 & 4264.6 & 6070.4 & 8470.2 & 20.5 \\
\hline Hypertension & 1595.3 & 2704.1 & 2689.2 & 3709 & 6716.2 & 32.3 \\
\hline $\begin{array}{l}\text { Ischemic heart } \\
\text { disease }\end{array}$ & 909.5 & 973.7 & 995.8 & 1236.8 & 1254.5 & 8.9 \\
\hline
\end{tabular}

disease. The growth of the given nosology form during the study period reached $8.9 \%$ (909.5 and 1254.5, respectively) - Table 3.

Dynamics study of newly identified diseases in the nosological forms found an increase by $13.2 \%$ (from 1043 in 2011 to 1721.2 in 2014 on 100,000 of adult population). So on the first rank place are diseases characterized by high blood pressure (385.9 in 2011 and 793.9 in 2015), the second ranking place is ischemic heart disease. Indicators of coronary heart disease had wave like character of growth and decline. The maximum value was observed in 2015 (of 258.2 per 100,000 people), the minimum in 2014 (154.3 per 100,000) (Fig. 3).

One of the important indicators, characterizing the health status of the population is the indicator of disability.

We have studied the dynamics of primary disability due to cardiovascular diseases among the dispensary patients of working age per 100,000 population municipal polyclinic No. 4 of Aktobe city, for the period from 2011 to 2015. In the structure of primary disability

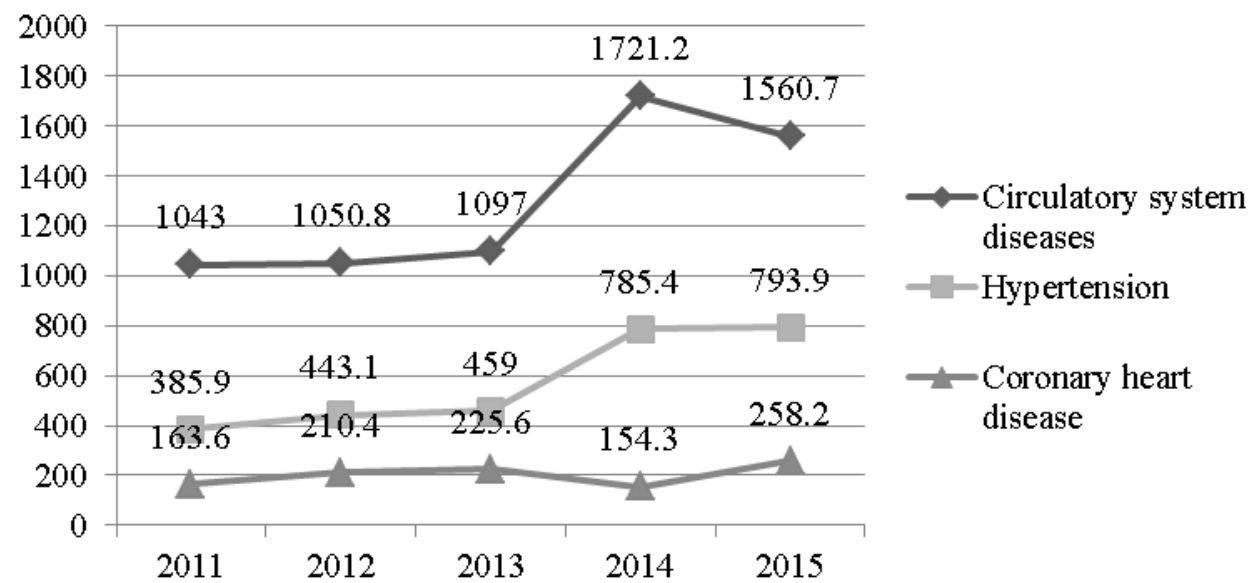

Figure 3. Dynamics of primary morbidity of the circulatory system diseases of the adult population in municipal polyclinic No. 4 of Aktobe according to nosological forms for 2011-2015 (per 100,000 people).

by main classes of diseases, growth rate of circulatory system diseases consistently holds a leading place, on the second rank place - neoplasm, and the third - diseases of the nervous system. So during the studied period the increase of diseases of the circulatory system accounted for $15.1 \%$ of neoplasm $-8.0 \%$, and diseases of the nervous system $-2.9 \%$.

Received results are presented in Table 4. 
Table 4. The structure of primary disability by main categories of diseases among adult population of municipal polyclinic No. 4 of Aktobe for 2011-2015 (\%).

\begin{tabular}{|l|c|c|c|c|c|c|}
\hline \multirow{2}{*}{ Classes of diseases } & \multicolumn{5}{|c|}{ Years } & $\begin{array}{c}\text { Temp } \\
\text { growth in } \\
\text { \% }\end{array}$ \\
\hline $\begin{array}{l}\text { Total on the main } \\
\text { classes of diseases }\end{array}$ & 100.0 & 100.0 & 100.0 & 100.0 & 100.0 & \\
\hline $\begin{array}{l}\text { Diseases of the } \\
\text { circulatory system }\end{array}$ & 9.3 & 13.5 & 20.5 & 12.7 & 21.4 & 15.1 \\
\hline Neoplasms & 18.6 & 32.4 & 31.3 & 18.3 & 36.7 & 8.0 \\
\hline $\begin{array}{l}\text { Diseases of the } \\
\text { nervous system }\end{array}$ & 13.9 & 21.6 & 12 & 19.7 & 17.3 & 2.9 \\
\hline
\end{tabular}

Out of initially recognized disabled in $2011,11.2 \%$ are of working age, the number of which in 2012 amounted to $8.9 \%$, that increased this figure by $2.3 \%$ from the previous year. And in the next 2 years, reduction in the yield on the primary disability from $6.5 \%$ in 2014 to $4.2 \%$ in 2015 is marked (Fig. 4).

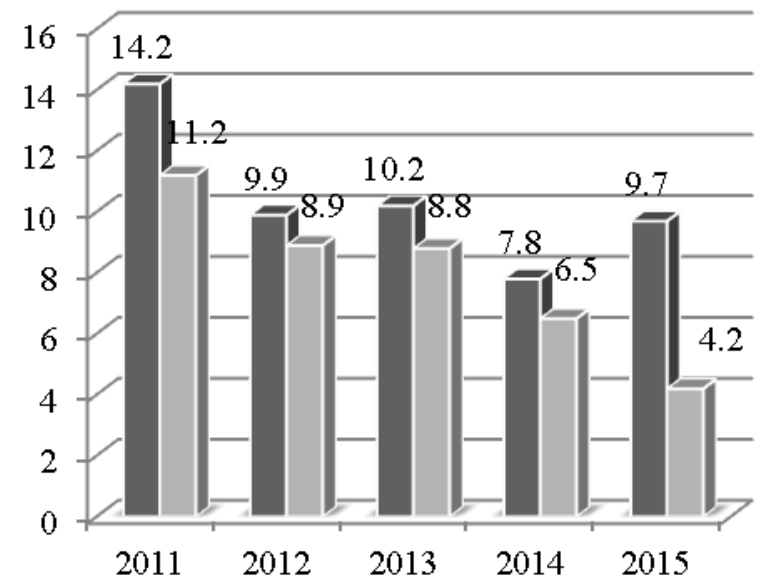

- Total number of disabled (\%)

out of them of working age $(\%)$

Fig. 4. Indicators of primary disability of the population of municipal polyclinic No. 4 of Aktobe for 2011-2015.

Significance of distribution of working-aged disabled people with diseases of circulatory system by disability groups are presented in Table 5 .

Table 5. Distribution of working-aged disabled people with diseases of circulatory system by disability group in municipal polyclinic No. 4.

\begin{tabular}{|c|c|c|c|c|c|c|c|c|c|c|}
\hline & $\mathbf{2 0 1 1}$ & \multicolumn{2}{|c|}{2012} & \multicolumn{2}{c|}{$\mathbf{2 0 1 3}$} & \multicolumn{2}{c|}{$\mathbf{2 0 1 4}$} & \multicolumn{2}{|c|}{2015} \\
\hline & abs & $\mathbf{\%}$ & abs & $\mathbf{\%}$ & abs & \% & abs & \% & abs & \% \\
\hline I group & 10 & 14.7 & 9 & 13.6 & 10 & 13.7 & 8 & 13.5 & 2 & 4.7 \\
\hline II group & 25 & 36.7 & 25 & 37.9 & 31 & 42.4 & 28 & 47.4 & 25 & 58.1 \\
\hline III group & 33 & 48.5 & 32 & 48.5 & 32 & 43.9 & 23 & 39.1 & 16 & 37.2 \\
\hline Total number & \multicolumn{3}{|c|}{68} & \multicolumn{2}{|c|}{63} & \multicolumn{2}{c|}{59} & \multicolumn{2}{|c|}{43} \\
\hline
\end{tabular}


Among recognized as disabled for the first time in 2011-2015 dominated the group III with a maximum value in $2011-48.5 \%$.

The decline in output in the primary disability is firstly associated with the indicator of the effectiveness of rehabilitation. Received results are presented in Table 6.

Table 6. The effectiveness of rehabilitation of disabled of municipal polyclinic No. 4 for 2011-2015.

\begin{tabular}{|l|c|c|c|c|c|c|c|c|c|c|}
\hline & \multicolumn{2}{|c|}{2011} & \multicolumn{2}{c|}{2012} & \multicolumn{2}{c|}{2013} & \multicolumn{2}{c|}{2014} & \multicolumn{2}{c|}{2015} \\
\hline & abs & \% & abs & \% & abs & \% & abs & \% & abs & $\%$ \\
\hline $\begin{array}{l}\text { Transferred from } \\
\text { group I to group II }\end{array}$ & 5 & 45.5 & 8 & 44.4 & 2 & 6.9 & 7 & 29.1 & 2 & 6.2 \\
\hline $\begin{array}{l}\text { Transferred from } \\
\text { group II to group III }\end{array}$ & 2 & 18.1 & 3 & 16.7 & 15 & 51.8 & 8 & 33.3 & 15 & 46.9 \\
\hline $\begin{array}{l}\text { Recognized as able- } \\
\text { bodied }\end{array}$ & 4 & 36.4 & 7 & 38.9 & 12 & 41.3 & 9 & 37.6 & 15 & 46.9 \\
\hline $\begin{array}{l}\text { Total number } \\
\text { rehabilitated }\end{array}$ & \multicolumn{3}{|c|}{11} & \multicolumn{3}{|c|}{18} & \multicolumn{3}{|c|}{29} & \multicolumn{2}{|c|}{24} & \multicolumn{3}{|c|}{32} \\
\hline
\end{tabular}

The data presented in Table 6 of the effectiveness of rehabilitation of working-aged people with disability indicates that the rate of recognized capacity to work has grown from $36.4 \%$ in 2012 to $46.9 \%$ in 2015 while the number of the rehabilitated grows by every year.

Thus, we can draw the following conclusions:

1. Among the patients who are on the dispensary due to the diseases of the circulatory system, women are dominated and their number is growing every year (from $55.8 \%$ in 2012 to $64.4 \%$ in 2015 year).

2. Annually, among the population a tendency for increasing of diseases of the circulatory system by $8.18 \%$ is observed, which is also confirmed by the growth rate of TPR $=$ $+4.7 \%$.

3. In the structure of morbidity of diseases of the circulatory system the leading place is occupied by patients with high blood pressure and coronary heart disease.

4. In the structure of primary disability for the main classes of diseases, diseases of the circulatory system show a stable growth rate.

5. The indicator growth of people, recognized as able-bodied contributed to the decline in output in the primary disability (from $36.4 \%$ to $46.9 \%$ ), indicating the efficiency index of rehabilitation of patients with diseases of the circulatory system.

The obtained results once again confirm the significance of the preventive and therapeutic measures among patients with diseases of the circulatory system with the objective of reducing rates of disability and mortality among this category of patients.

A study conducted by Heidenreich et al. [9] also highlighted the prevalence of the cardiovascular diseases in the USA indicating the growing proportion in the health expenditure of the country. Moreover, the study forecasted the substantial increase in the prevalence and costs of care for cardiovascular diseases, particularly hypertension and coronary heart disease, until 2030. Also it has been suggested that prevention and early intervention are the key factors in decreasing both the prevalence and mortality from diseases of the circulatory system which have been confirmed in this study.

According to Townsend et al. [10] cardiovascular diseases are responsible for $45 \%$ of deaths in Europe and the majority of them are coronary heart diseases. These numbers justify the need for continuous study of the dispensary patients. Also they reported the $56.5 \%$ decrease in mortality from cardiovascular diseases in Kazakhstan in ten years (from 2002 to 2012). Despite the fact that the mortality and prevalence are different indicators, to some extent it can be viewed as consistent with the results of this study. 
Another finding provided by Finegold et al. [11] implies that diseases of the circulatory system in the working age population are much higher in developing countries than in developed ones. This causes an additional challenge for the countries like Kazakhstan taking into account the increasing costs in the future projected by Heidenreich et al.

In conclusion, the results of this study are in line with other studies that have investigated morbidity, disability and mortality from circulatory system diseases. As the information systems that have been implemented in recent years may have had an impact on the statistics, as well as on the healthcare system in general, the comparison between before and after intervention periods of the abovementioned electronic portals and registers could be explored in future studies.

\section{References}

1. Ekkert N.V., Mihajlovskij V.J. Sibirskoe medicinskoe obozrenie Sovremennye problemy i puti povysheniya ehffektivnosti mediko-social'noj reabilitacii invalidov vsledstvie boleznej sistemy krovoobrashcheniya (na primere Tul'skoj oblasti) 2, 77$81(2015)$

2. Gohlke H. Is it worth offering cardiovascular disease prevention to the elderly? Eur J Pre Cardiol. 20, 121-6 (2013)

3. Abdikadirova I.T., Ermukhanova L.S., Bekbauova A.U., Umbetov M.U. The use of automated control systems in dispensary observation of patients in Aktobe city. J. MEDICINE (Almaty). 4(166), 6-8 (2016)

4. Lisitsyn Y.P., Ulumbekova G.E. Obshchestvennoye zdorov'ye i zdravookhraneniye GEOTAR-Media (2014)

5. Abdikadirova I.T., Ermukhanova L.S., Ibrasheva A.Z., Umbetov M.U. Evaluation of automated control systems at the primary health care. J. Vestnik KazNMU. 1, 650653 (2016)

6. The top 10 causes of death [Electronic resource] // Mediacentre of WHO. - Fact sheet 310 (2014) Available at: http: / / www . who. int/mediacentre/ factsheets/fs310/en

7. Piccolo R., Giustino G., Mehran R., Windecker S. Stable coronary artery disease: revascularization and invasive strategies. The Lancet. 386(9994), 702-713. http://dx.doi.org/10.1016/s0140-6736 (15) 61220-x (2015)

8. Izet Masic and Jasmin Alajbegovic. The Significance of the Psychosocial Factors Influence in Pathogenesis of Cardiovascular Disease. Int J Med. 4(11), 1323-1330 (2013)

9. Heidenreich P.A., Trogdon J.G., Khavjou O.A., Butler J., Dracup K., Ezekowitz M.D., ... \& Lloyd-Jones D.M. Forecasting the future of cardiovascular disease in the United States. Circulation. 123(8), 933-944 (2011)

10. Nick Townsend, Lauren Wilson, Prachi Bhatnagar, Kremlin Wickramasinghe, Mike Rayner, Melanie Nichols; Cardiovascular disease in Europe: epidemiological update 2016. European Heart Journal. 37(42), 3232-3245 (2016)

11. Finegold J.A., Asaria P., \& Francis, D.P. Mortality from ischaemic heart disease by country, region, and age: statistics from World Health Organisation and United Nations. International journal of cardiology. 168(2), 934-945 (2013) 